\title{
Erratum to: The efficacy of lymphatic drainage and traditional massage in the prophylaxis of migraine: a randomized, controlled parallel group study
}

\author{
Svenja Happe ${ }^{1,2} \cdot$ Andreas Peikert $^{3} \cdot$ Rudolf Siegert $^{4} \cdot$ Stefan Evers $^{5}$
}

Published online: 13 July 2016

(C) Springer-Verlag Italia 2016

\section{Erratum to: Neurol Sci}

DOI 10.1007/s10072-016-2645-3

Unfortunately, the acknowledgement section was missed in the original publication of the article.

The complete text is given below:

The authors wish to thank Minhal Hamzeh, MD for his invaluable contribution to this study by enrolling and treating patients.

The online version of the original article can be found under doi:10.1007/s10072-016-2645-3.

\section{Stefan Evers}

everss@uni-muenster.de

1 Department of Clinical Neurophysiology, Klinikum Bremen-Ost/University of Göttingen, Bremen, Germany

2 Department of Neurology, Krankenhaus Maria Frieden, Telgte, Germany

3 Private Neurological Practice, Bremen, Germany

4 Institute of Physical Medicine and Rehabilitation, Klinikum Bremen-Ost/University of Göttingen, Bremen, Germany

5 Department of Neurology, Krankenhaus Lindenbrunn, Coppenbrügge, Germany 